\title{
Suggestions on Writing for Publication in Language Learning Journals
}

\author{
George M. Jacobs \\ SEAMEO Regional Language Center, Singapore
}

\begin{abstract}
This article provides suggestions on writing for journals in the field of language learning. These suggestions are presented in the three sections. The first section discusses how to begin. Suggestions in this section are that we appreciate the benefits of writing for publication, develop good ideas, work efficiently, ponder options as to what type of writing to do, choose a good topic, consider replication of other's research, and cooperate with others. The second section presents suggestions on doing the actual writing. Here, it is suggested that we connect ideas, delve deeply into the ideas we present, strive to write the reader friendly manner, use visuals, and improve our writing by noticing how other journal authors write. The third section concerns relations with editors. The advice given is that we choose carefully the journal to which we submit our work, follow that journal's directions to contributors, include a cover letter, be prepared to wait patiently, welcome critical feedback from editors and reviewers, and view editors as colleagues.
\end{abstract}

Key Words: writing for publication, language learning journals

Journals play an important role in the language teaching profession by providing language educators with a forum to exchange and develop ideas. Indeed, the quantity and quality of journals in a professional field stands as an indicator of the growth and level of excellence achieved in that field. Thus, we need to promote our profession by providing good quality articles for our journals to publish. From an individual perspective, I have found writing for language learning journals to be an enriching and fulfilling, although at times humbling and frustrating, experience. This article brings together what I have read and heard from others on the topic of 
writing for language learning journals with my own limited experience in this pursuit.

The article divides suggestions for publishing in language learning journals into three parts. The first part presents seven suggestions for how we can get started finding ideas for what to write and how to work to improve on these ideas. The second part presents five suggestions for how to write up our ideas. The third and final part discusses six suggestions for how to choose a journal to write for and how to collaborate successfully with journal editors. Suggestions from the various parts sometimes overlap.

\section{GETTING STARTED}

\section{Appreciate the Benefits of Writing for Publication}

When we write for language learning journals, we benefit ourselves and others. Our students benefit in several ways. Firstly, if we are writing for journals, when we ask our students to write in class, it is not a case of "Do as I say, but not as I do", because we can show with them that we are "doing" too, by sharing with them about our own writing. In this way, we serve as a model and show that writing is not just something people do as a course assignment. Also, as we are writers too - facing the difficulties that all writers face, such as developing ideas, finding the right words to express our ideas, and facing sometimes unfavorable feedback - we may be slower to criticize our students, more accepting of their faults, and more insightful in the advice we offer.

Secondly, as noted in the introduction to this article, writing for publication benefits our field as we add our perspective on the problems language educators confront. Language teaching is not an easy task, especially in foreign language contexts. Thus, we need all the good ideas we can develop, and journals provide an excellent means of exchanging our good ideas with others in the profession. In the particular case of English teaching in Indonesia, most of the books and articles teachers read are - like the article you have kindly chosen to read now - written by those outside Indonesia and who are-like the author of the present article - native speakers. More Indonesian and more non-native speaker voices need to be heard.
Finally, we ourselves profit in many ways by writing for publication. One, we improve our writing ability. Two, we become better educators by thinking more about what we do and pressuring ourselves to practice what we preach. For instance, if I write an article about using groups in reading instruction, this pushes me to really use groups and to use them well when I teach reading. Three, when our article does get published, our professional self-esteem rises. Also, we can develoop new contacts when we receive comments from those who read our article, although it is my unhappy experience that most articles do not result in mail from readers or much face-to-face feedback from colleagues at our own institutions.

\section{Start with Good Ideas}

Just as in the process approach to writing the first phase is to develop ideas for our topic (White \& Arndt, 1991), when we write for publication, we need to begin with some good ideas to write about. When many people think about journal articles, they think the only path to take is to write an article that reports research finding. However, formal research is only one of many ways of getting ideas.

Other means of finding good ideas are:

1. Are you using any teaching methods or techniques that some other educators may not be aware of or may have only heard of but not know how to use well? These do not have to be methods or techniques which you invented. Rather, the key is whether they offer something new and useful to an important portion of the readers of a particular journal.

2. Do you have an opinion about some ideas presented in a previous issue of a journal? Just because an idea appeared in print, even if it was in an article written by a "big name", does not make it correct, or maybe the idea is appropriate to some learning environments but not to others. Debate is healthy; we can learn from reasoned disagreement in which we criticize ideas, not people.

3. Have you learned about an idea from another field that you think would be useful for second language educators? Our field receives many ideas from outside. For instance, the concept of the process approach to writing came from cognitive psychology and was later applied to language teaching.

4. Research is no longer the exclusive domain of university professors who en- 
ter the language classroom not to teach but only to collect data. With the increasing use of action research and other tools for reflective teaching (Richards and Lockhart, 1994), classroom practitioners are also doing research.

\section{Be Efficient}

To write an article, we do not need to start from scratch. Instead, we can take work we have already done and develop it into an article. For instance, every year the TEFLIN organization hosts a national conference, as well as regional conferences. Many papers and workshops are presented at these events. These presentations can serve as very good foundations for articles. Indeed, the article you are reading now began its life as workshop I was invited to present to faculty at Universiti Technologi Malaysia, in Johor Bahru, Malaysia.

Similarly, materials we prepare for courses can become the starting point for publications. Such articles are often of great interest, because we teachers enjoy looking into each others' classrooms in search of good ideas. For example, my colleague Patrick Gallo developed some checklists to help his students provide peer and self feedback on the speeches they gave in a class he was teaching on presentation skills. We used these checklists as the foundation for a chapter in a book on assessment published by the TESOL (Teachers of English to Speakers of Other Languages) organization (Gallo \& Jacobs, 1998).

Work done by students can also form the basis for publications. For instance, we may have asked our students to write about their views on language policy or about their learning strategies. Such writing topics are in line with moves in language education to give students a greater understanding of and role in the learning process (Pemberton, 1996). Or, perhaps our students (especially if we teach pre-service or in-service teachers) have done some original research of their own into issues of interest to language teachers, e.g., what kind of reading they or their students do outside of class. This research can be the basis for an article, but we have to be careful to give the students credit for their work, perhaps having them be co-author or even first author, depending on their contribution to the final article.

\section{Consider Options Besides the Typical Article}

Journals differ from one another, and within each journal we find different types of pieces besides the standard article. Some of these other types of pieces found in journals include:

1. reviews of books, CD-ROMs, websites, and other materials

2. opinion pieces

3. responses to previous pieces in an issue of the same journal, e.g., once I wrote a piece for TESOL Matters to state my disagreement with an opinion piece they had published (Jacobs, 1993)

4. letters to the editor

5. teaching tips and lesson plans

\section{Choose a Good Topic}

Writing an article or other piece for a journal often requires a good deal of effort. To make this effort worthwhile, we need to spend some time choosing a good topic. Firstly, the topic should be meaningful to us, i.e., something that we feel is important. Second, it should be a topic of interest to others. We can get an idea of what the "hot" topics are by looking at recent issues of journals. At the same time, our ideas do not have to be so very new, because there are scores of journals, and nobody reads them all; besides, good ideas are worth repeating in new contexts and with new twists.

\section{Replicate}

When I'm going to do research as the basis for an article, I look around for other research similar to the study that I envision. Research can loosely or closely follow the design used by others, even if the topic is different. Replication seems like the lazy way to do research, but master's degree students here at RELC and I have attempted to do replications, and I assure that it is not easy, because understanding and carefully repeating research in another context is a difficult task. Further, our field benefits from replication, because we need multiple studies 
of the same question done by different researchers in different context with different types of students in order to have much confidence in a particular finding. Also, replication can be a good way for less experienced researchers to learn how to plan and conduct good quality investigations.

\section{Cooperate with Others}

Writing is a hard job, but as the saying goes, "Many hands make light the work", and as another saying goes, "Two heads are better than one". Look at a recent issue of a leading journal and you will probably see that many of the articles have multiple authors, and even many of the single-authored articles list several people in the Acknowledgements section. Colleagues can provide feedback on first content and then form, and we can do the same for their writing - it's just like in the process approach to writing. Faculty in other departments can help too, e.g., lecturers in statistics can help with designing and analyzing the data from quantitative research, or those with a social sciences background can provide their perspective when it comes to qualitative research.

We can find collaborators from many other sources as well. Networks can be formed with people who:
1. we met at conferences
2. have written on similar topics
3. belong to the same internet discussion list
4. teach a course on the same or a related topic, or
5. belong to the same professional organization.

We should reach out to others. Some may not respond, but now more than ever with the ease of email, worldwide cooperation happens, especially when we show we have helped ourselves before asking others for help. Further, with today's trends toward learner-centred teaching, metacognition, learner strategies, and qualitative research, students can also be our collaborators.

When others join us in working on the article, rather than just giving their advice, the question arises of who will be listed as authors of the publication and in what order the names will be listed. This matter should be discussed at the begin- ning of the collaboration. Only people who make a significant professional (rather than, e.g., clerical) contribution should be authors. Normally, the person who makes the most important contribution is first author. People who helped but are not.authors should be included in a very brief acknowledgements section.

\section{WRITING UP OUR IDEAS}

Once we have some good ideas and have consulted with others via books and journals, written communication, face-to-face meetings, and other means, we are ready to write our piece. Of course, the act of writing itself can help us get ideas, and we may often find in the course of our writing that we need to go back and get some new ideas or revise the ones we started with. Below are five ideas that I try to keep in mind in my own writing.

\section{Connect Ideas}

An article should be a rich tapestry, connected both within itself and to the ideas of others. We should connect our ideas to other people's writing in many related areas, including others' research, theory, methodology, philosophy, and techniques. Also, we will often want to link our ideas to practical, real-life examples. In this way, we create a bond between the concrete and the abstract. For instance, if we mention a theoretical idea in an early part of our article, we might later show in a very, very clear manner how we put that idea into practice in our classroom. Thereby, we connect the various parts of our article, giving every idea a purpose, making it a necessary part of the whole.

\section{Don't Just Present Data and Experience: Ize Them}

One tool for connecting ideas is to apply some of the thinking strategies embodied in words ending with the sound ize: analyze, synthesize, generalize, organize, conceptualize, concretize, and, to invent a new word, exemplifize. Such izing provides depth to our writing, making it easier to understand and more mean- 
ingful. Another ize word is recognize; we need to recognize that ideas in disagreement with our own often exist. Instead of ignoring these, we should present them and verbalize why we see things differently.

\section{Be Reader Friendly}

How many times have you heard fellow educators and maybe yourself complain about journal articles, protesting that they are difficult to understand and written for specialists only? So that no one makes the same complaint about out articles, we must try to write in a reader-friendly manner. Some ways to achieve this are: furnish background and explanation for those not from our country/institution explain terms and concepts for those not involved in the same specialty area in our field, e.g. readers should not have to be assessment experts to understand the general ideas in an article on assessment; write introductions to the article as a whole and to each section, these help prepare readers for what is to come; establish a smooth flow from one section to another and from one paragraph to another in order that readers can better understand how our ideas connect and what our main points are.

\section{Use Visuals}

Another way of being reader friendly is to illustrate our ideas with visuals. Visuals are nice to look at and can make ideas easier to understand. Visuals include tables, graphs, drawings, diagrams, photos, samples of students' writing in their original handwriting, boxes, and textual enhancement, e.g. bold, italics, and underline. Journal editors usually need camera ready copies of all visuals, but advances in computer software make it easier to create visuals. In an article on conducting research that I co-authored with Willy A. Renandya of Akademi Bahasa 17 (Jacobs, Renandya, and Das, 1997), we included drawing to illustrate our suggestions.

The visual in Figure 1 summarize the key points in this article.

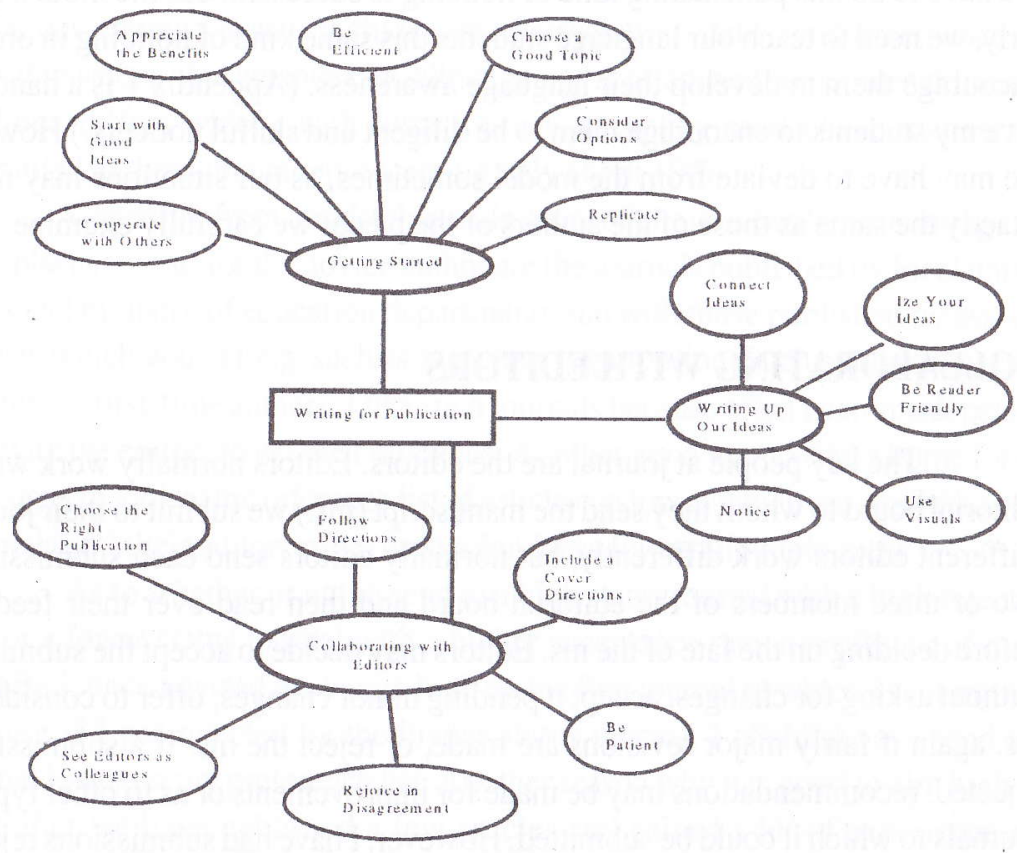

Figure 1. Mindmap of Suggestions on Writing for Publication in Journals

Notice

A very good way to figure out such writing matters as how to divide our piece into sections and how to phrase our ideas is to look very carefully at a similar piece in the journal for which we plan to write and notice how they do these things. For example, if we are writing an article reporting research, we can find an article in that journal or a similar journal which reports research. What are the subheads? What is the wording used to report the results? We can copy much of this. That is not plagiarism.

Every field has certain conventional ways of writing. Probably the simplest way of learning these conventions is to find a model, take out our magnifying 
glass, and examine very closely its parts and the language it uses, e.g., the tenses. We have to do this painstaking kind of noticing to successful use the model. Similarly, we need to teach our language students this same kind of noticing in order to encourage them to develop their language awareness. (Appendix 1 is a handout I give my students to encourage them to be diligent and skilful noticers.) However, we may have to deviate from the model sometimes, as our situations may not be exactly the same as those of the authors of the pieces we carefully examine.

\section{COLLABORATING WITH EDITORS}

The key people at journal are the editors. Editors normally work with an editorial board to whom they send the manuscript (ms.) we submit to their journal. Different editors work differently, but normally editors send each submission to two or three members of the editorial board and then read over their feedback before deciding on the fate of the ms. Editors may decide to accept the submission without asking for changes, accept it pending minor changes, offer to consider the $\mathrm{ms}$. again if fairly major revisions are made, or reject the ms. If a submission is rejected, recommendations may be made for improvements or as to other types of journals to which it could be submitted. However, I have had submissions rejected without any reasons or advice given.

Because editors are such important people, we need to know how to work with them. Below are five suggestions on how to do that. I have never been a journal editor, but I have edited books and currently serve on the editorial board of two journals, including TEFLIN Journal. So, I do have some sympathy for this often maligned species.

\section{Choose the Right Publication}

There exists a very wide variety of journals, with each area of education and related fields having its own journals, e.g., psychology, the Thai language, pragmatics, distance education, first language acquisition, and second language writing instruction. Additionally, some journals focus on specific places e.g., a country or region, while others are international in scope. Publications also vary in terms of their orientation, e.g., from mainly theoretical to mainly practical and from emphasizing quantitative research to specializing in qualitative research. Other variations among journals include size of circulation, status, and acceptance rate for submissions. Acceptance rate, although not constant and sometimes difficult to find out, differs widely, with some journals accepting most of the manuscripts submitted to them, but others accepting only about $10 \%$.

Choosing from amidst this wide array of choices can be a daunting task. Two places to start for the novice author are the journals published by local universities and ministry of education departments and with those published by associations to which you belong, such as a teachers organization. Such publications often encourage first-time authors. I like such journals because often I can speak personally with the editors to get their guidance. Another good way to find a home for our writing is to look at the reference list of articles on topics which are similar to ours. Journals and their editors often have a fondness for certain topic areas.

As to whether or not to send to a high status journal with a high rejection rate or a lower status journal with a higher acceptance rate, a professor of mine, Fred Bail, once advised me to aim high on the first journal to which I sent my ms., because if I got rejected by the higher status journal, I could always send to a journal lower on my preference list. Another reason why it is good to aim high - at least after we have published a few articles and gained a bit of experience and confidence - is that, at least in my limited experience, the more prestigious journals often give better feedback, even when they reject an article. For instance, once I sent a ms. on cooperative learning to TESOL Quarterly only to have it sent back with a rejection letter. I kept the feedback from the reviewers and have referred to it since whenever I write something about cooperative learning.

Another point to keep in mind is that one study can result in more than one article. For example, in many studies, such as a study that records studentstudent interaction in groups, large quantities of data are produced. These data can be analyzed to answer a variety of research questions. These questions can be grouped, with each group forming the basis for a separate article. Additionally, we can write two very different pieces on the same topic, e.g., one piece could emphasize theory and research and be submitted to a journal with that slant, while a more practical article could be written for submission to a journal with a practical focus. 


\section{Follow the Directions Given in the Guide to Contributors}

Most publications provide guidelines to potential authors in a section entitled something like Guidelines for Contributors. The guidance deals with such matters as:

1. length of manuscripts in words or pages

2. size of margins

3. line spacing, e.g., double-spaced

4. number of copies to submit

5. format of references, subheads, etc.

6. whether an abstract is required

7. other times to enclose, e.g., diskette and author(s)' biodata, institutional affiliation, or photo

8. a statement that the ms has not been published or is being considered for publication elsewhere.

Also, I have learned the hard way to keep a copy of my ms. Sometimes, I get feedback from editors that refers to particular page and line numbers. If I don't have an exact copy of what I sent, I can't always find what they are referring to.

\section{Include a Cover Letter}

We need to be sure to include a cover letter to accompany our ms. Cover letters will normally contain the title of the ms. and contact information for the first author- mail, phone, fax, email, and carrier pigeon(?). I also request that the editor send me acknowledgement of receipt of the ms., although most, but not all, journals do this routinely. Another thing I learned the hard way is to include in the cover letter a list of all the authors with their names in the form and order in which they should appear if the article is published.

\section{Be Patient}

Once we have submitted our ms., the waiting begins. I have waited more than a year for a response to an article I submitted, and I've heard even worse cases. However, most journals take less than six months, but few take less than about three months. Editors should give us some idea how long we will have to wait when they write us to acknowledge receipt of our ms. Of course, when we do receive feedback from the journal it may be in the form of a request to rewrite. That means we will have to resubmit and then wait all over again. If at last, our piece is accepted we often have to wait at least another six months, but often a year for it to be published. Thus, an article we submit in 1999 may not be published until 2001, and that is not taking into the account that we may have to submit our ms. to two or three journals before getting it accepted.

\section{Rejoice in Disagreement}

One of the most difficult experiences I have when writing for language learning journals occurs when I get conflicting feedback from two reviewers from the same journal. For instance, one praises an idea in a piece I $\mathrm{co}$-authored and the other says that the same idea should be deleted. I have had one reviewer recommend that an a ms. be accepted with minor revision and another recommend that it be rejected. Reviewers suffer from the same problems as everyone else: bias, political machinations, failure to notice major errors, and inconsistent standards of judgement (Peters and Ceci, 1982).

If our ms. gets rejected by a journal, no matter how stupid their reasons may seem, we should pause to think about them. After all, the members of the editorial board are members of our profession, in other words, members of our intended audience. Perhaps, we need to rewrite to better reach this portion of our audience. Also, as I recounted in my experience with TESOL Quarterly, there may be good advice accompanying our rejection letter. And, remember as the $19^{\text {th }}$ century novelist Anthony Trollope wrote, "There is no way of writing well and also of writing easily".

If we are asked to make revisions, we should be willing to compromise to try to satisfy the suggestions of the editor and reviewers. However, we do not need to follow all their suggestions, and, as was mentioned above, sometimes we cannot follow all their suggestions because reviewers disagree with each other. When we decide not to follow suggestions, we should clearly state our reasons for not wanting to make a particular change. In other words, we should see disagreement as an opportunity to think more deeply. As the saying goes, "If everyone is thinking alike, someone isn't thinking". 


\section{Treat Editors Like Colleagues}

Finally, we need to realize that we, the authors, sink or swim together with editors - if our piece is good, it makes everyone associated with it happy, but if what we have written is not very good, everyone looks bad, us and the editors. Editors do not enjoy rejecting articles, because it means they have less good materials for their journal. When a ms. arrives in their mailbox which has followed all the requirements spelled out tin the Guidelines for Contributors and does not need any content or style changes, editors are "living on Easy Street". But, every extra draft we have to do is more work for those who have to give us feedback.

We should realize that editors are busy too. Most or all of them have fulltime jobs, and editing a journal means extra work. Therefore, just as we hope they will forgive our inadequacies, e.g. taking a couple extra months to send in our revised $\mathrm{ms}$., so too should we forgive their inadequacies, e.g. taking a couple extra months to send out the feedback on our revised ms. Regular correspondence with editors keeps the communication lines open. For instance, we should let them know about new addresses and if we fall behind schedule in sending in revisions, camera ready graphics, etc. we should inform them that we have not decided to forget about the article and change careers from language educator to Antarctic explorer talking with penguins.

On that somewhat sarcastic note, I will bring this article to an end. I hope that reading this advice has left you inspired not tired, elated not deflated; and thrilled not chilled. Writing for publication in journals and other media plays an important role in our important profession. You are an important member of that profession. I look forward to reading your articles. Happy writing!

\section{REFERENCES}

Gallo, P.B. and Jacobs, G.M. 1998. Gradually Growing Presentation Assessment. In J.D Brown (Ed.), New Ways in Assessment (pp. 38-39). Alexandria, VA: TESOL

Jacobs, G.M. 1993. Language Use, or Language Usage? TESOL Matters, 3:6. 15.

Jacobs, G.M., Renandya, W.A., and Mohandas, P. 1997. Suggestions For Conducting
Graduate Research. Studies In Language And Language Teaching 7: 43-58.

Pemberton, R. (Ed.). 1996. Taking Control: Autonomy in Language Learning. Hong Kong: Hong Kong University Press.

Peters, D.P. and Ceci, S.J. 1982. Peer-Review Practices of Psychological Journals: The Fate of Published Articles, Submitted Again. Behavioral and Brain Sciences 5:2: 187-2

Richards, J.C. and Lockhart, C. 1994. Reflective Teaching in Second Language Classrooms. Cambridge: Cambridge University Press.

White, R. and Arndt, V. 1991. Process Writing. London: Longman.

\section{RELATED READINGS}

American Psychological Association. 1994. Publication Manuals of The American Psychological Association (4th ed.). Washington, DC: Author. [One of several wellknown manuals providing a very detailed model of how to write for publication, including how to do references.]

Benson, M.J. 1994. Writing an Academic Article: an Editor Writes. English Teaching Forum 32. 6-9, 25.

Brown, J.D. 1988. Understanding Research in Second Language Learning. Cambridge: Cambridge University Press. [Chapter 5 discusses the features of an article reporting quantitative research.]

Cherry, R.D. and Walters, K. 1991. Editors' Comments. Written Communication 8:1. 3-6.

Cleghorn, A. and Genesee, F. 1984. Languages in Contact: an Ethnographic Study of Interaction in an Immersion School. TESOL Quarterly 18:4. 595-625. [An example of an article reporting qualitative research.]

Day, A. 1996. How to Get Research Published in Journals. Aldershot, Hampshire: Gower. Henson, K.T. 1991. Writing for Successful Publication. Bloomington, IN: National Educational Service.

Morrow, K. 1996. Getting Into Print With ELT Journal. Paper presented at The Annual Conference of International Association of Teachers of English as a Foreign Language, York.

Nunan, D. 1992. Research Methods in Language Learning. Cambridge: Cambridge University Press. [Provides ideas for doing different types of research.]

Peck MacDonald, S. 1994. Professional Academic Writing in The Humanities and Social Sciences. Carbondale, IL: Southern Illinois University Press.

Woods, D. 1989. Studying ESL Teachers' Decision-Making: Rationale, Methodological Issues and Initial Results. Carleton Papers in Applied Language Studies 6. 107-123. [An example of an article reporting qualitative research.] 
The author gratefully acknowledges the helpful suggestions of Kathi Bailey, Yolanda Beh, George Braine, and Keith Morrow, as well as all the editors he has had the pleasure and displeasure of working with (but more of the former) and to whom he, similarly, has provided pleasure and displeasure (hopefully slightly more of the former).

\section{APPENDIX 1}

Below is a handout I use in a writing course at SEAMEO RELC.

\section{NOTICING}

I have never been to India and have seldom been in Indian people's homes, so I was not sure how to behave. Thus, I was very careful to notice and copy what other people did. When Mr Rajan took off his shoes, I took off mine. The family had prepared an excellent home-cooked meal of Indian food - one of my favorites. When we sat down to eat, I saw everyone eating with their hands. I have done that before but very seldom. So, I carefully noticed how Mr Rajan put a small amount of food on his finger tips and used his thumb to push it into his mouth. I also noticed that everyone used only one hand and always the same hand - I forget which one - to eat with. Then, as best I could, I copied their way of eating the delicious food.

I do the same kind of noticing and copying when I write. For instance, as chair of RELC's research committee, I have to write several reports every year. When I first became chair, I asked Mr Khng, the RELC Assistant Director 1, for copies of the various reports prepared by the previous chair. I carefully noticed many features of these reports involving content, e.g., what type of research was reported and what aspects of the studies were described, and form, e.g., what kind of headings and punctuation were used. When I wrote my reports, I copied the features which I had noticed. Of course, I could not copy exactly because some things had changed. Please notice that: we cannot always copy exactly.

Here is another example of the power of noticing. The other day, I was reading on the Internet about one of my favorite singers. Bruce Springsteen from the U.S. I read that when he was a young teenager he loved rock music so much that every week he would write out the 20 most popular songs. I am sure that doing that helped him to learn how to be a great writer of rock music when he got older, because it helped him notice the key features of high quality rock songs.

When we read, we cannot notice everything. I only notice what is important to me at a particular time. Please try to start noticing when you read. Choose what language features you will try to notice, e.g., commas, introductions. Or, as you read, you may see something that stands out that you want to notice. What is vital is that you read a lot and that you become an aware reader. Let me say that again: What is vital is that you read a lot and that you become an aware reader 